\title{
ИССЛЕДОВАНИЕ МЕТОДОВ ПОДБОРА ВАКАНСИЙ НА ОСНОВЕ АССОЦИАТИВНОГО АНАЛИЗА ДАННЫХ
}

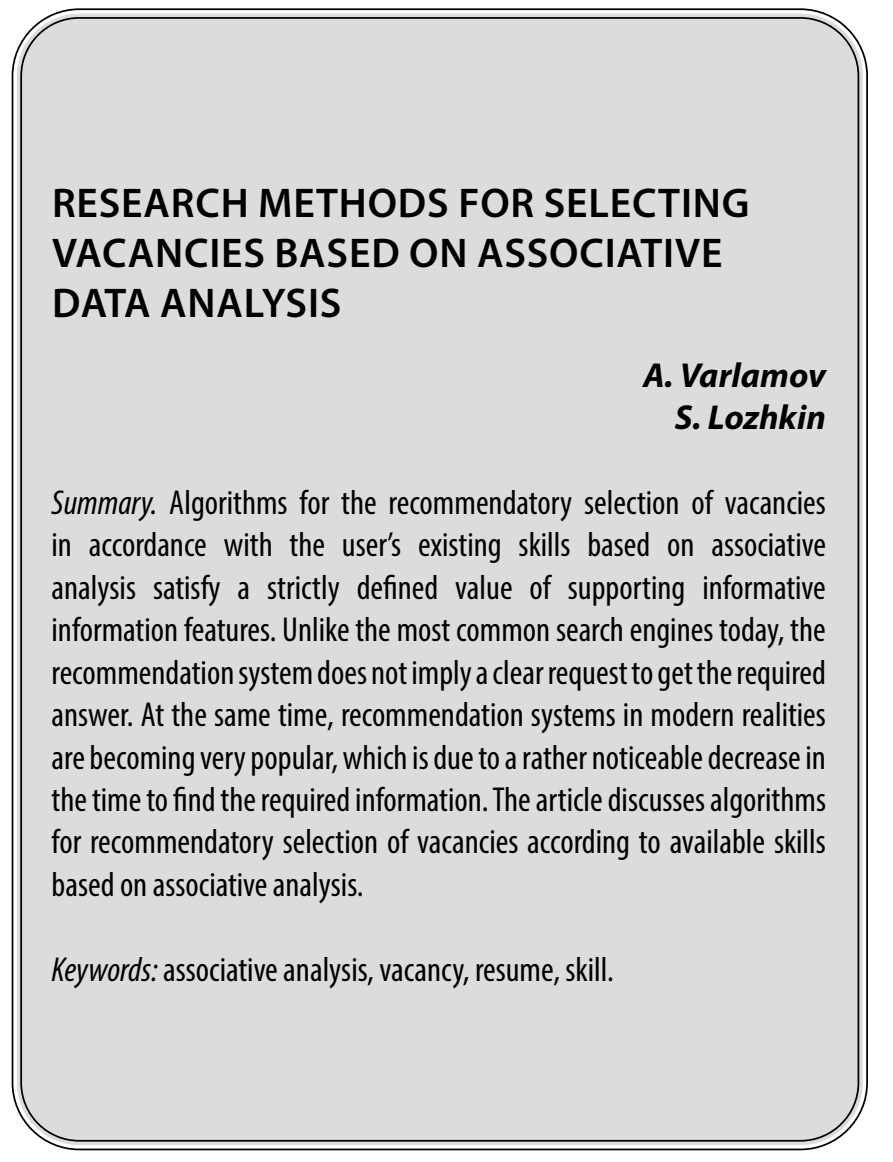

\section{Введение}

овременные информационные технологии - это еще и относительно новые способы для поиска работы, представленные сайтами, которые посвящены не только развитию карьеры, но и подбору вакансий. С этой точки зрения повышенное внимание уделяется такому наиболее важному показателю рекомендательного подбора вакансии в соответствии с имеющимися у пользователя навыками, как оценка точности, с которой предлагаются различные варианты трудоустройства по данным профайла. Безусловно, в некоторых случаях кандидатам могут предлагаться позиции вне рамок указываемых ими опций, но исключительно в тех случаях, когда работодателем указана готовность на выполнение работы с резюме таких пользователей.

В процессе поиска кандидата на вакантные должности работодатели заинтересованы в том, чтобы потенциальные сотрудники не просто имели желание работать
Варламов Алексей Дмитриевич

К.т.н., дочент, Муромский институт (филиал) ФГБОУ ВО «Владимирский государственный университет имени Александра Григорьевича и Николая Григорьевича Столетовых» varlamov_aleks@mail.ru

Ложкин Сергей Сергеевич

Муромский институт (филиал) ФГБОУ ВО «Владимирский государственный университет имени Александра Григорьевича и Николая Григорьевича

Столетовых» jlehuh213@ya.ru

Аннотация. Алгоритмы рекомендательного подбора вакансий в соответствии с имеющимися у пользователя навыками на основе ассоциативного анализа удовлетворяют строго определённому значению поддержки информативных информационных признаков. В отличие от самых распространённых на сегодняшний день поисковых систем, рекомендательная система не предполагает наличия чёткого запроса для получения необходимого ответа. При этом, рекомендательные системы в современных реалиях становятся очень востребованными, что обусловлено довольно заметным уменьшением времени на нахождение требуемой информации. В статье рассмотрены алгоритмы рекомендательного подбора вакансий согласно имеющихся навыков на основе ассоциативного анализа.

Ключевые слова: ассоциативный анализ, вакансия, резюме, навык.

в данной компании, но и обладали необходимыми навыками.

Персонализация вакансий осуществляется таким образом, чтобы получить отклик исключительно от наиболее подходящих претендентов на основе имеющихся навыков. Например, соискателю на узкоотраслевые вакансии необходимо ориентироваться на ожидаемые компетенции специалиста, чек-лист функциональных обязанностей и тестирование на наличие требуемых навыков, что является инструментом, хорошо подходящим для вакансий, где нужны узкоспециализированные знания.

Прежде чем приступить непосредственно к поиску вакансий, будет лучше, составить список мест поиска вакансии:

- газеты и журналы, в том числе и газета работа для вас, откуда можно почерпнуть информацию обо всех существующих вакансиях; 
- кадровые агентства, агентства по трудоустройству и бирж труда;

- потенциальные работодатели, у которых возможно появление вакансий.

Рынок труда в ІТ в целом несколько отличается от любых других рынков.

Также широко применяется аддитивный метод для оптимальной кандидатуры на вакансию. Исходя из этого можно применить аддитивный метод для выбора подходящий работы. Зачастую кандидатом, который собирается сменить свое место работы, учитывается следующие важные критерии:

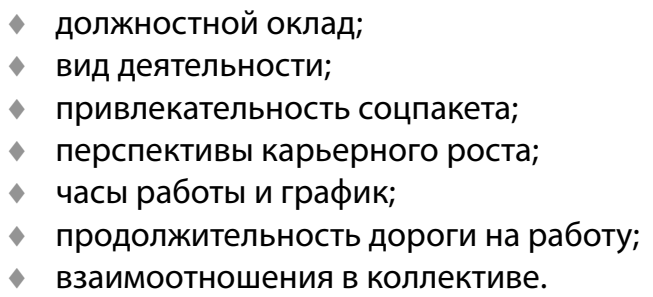

Каждый из этих критериев имеет свой вес. Исходя из этого, вакансия, которая набрала высший балл из всех возможных, является оптимальным вариантом для кандидата.

Каждый из таких подходов обладает собственными преимуществами и недостатками. Например, не охватывает полный спектр возможностей кандидата и ключевые аспекты выбираемой вакансии.

В подобной ситуации в обязательном порядке учитывается и важность рассматриваемых качеств соискателя для работы в конкретной сфере деятельности. При этом, на конкретном этапе оценке подлежат только личностные характеристики, так как нужно предполагать, что ключевые профессиональные качества и наличие специальных навыков уже были учтены предыдущими стадиями отбора.

Как показывает практика, все применяемые в настоящее время алгоритмы рекомендательного подбора вакансий, чаще всего успешно подстраиваются под клиентов по мере их обращения к таким системам, поэтому частота их использования обеспечивает получение лучших результатов.

Именно поэтому сегодня чаще всего в работе применяется ассоциативный анализ, обеспечивающий выявление связей между ключевыми критериями при выборе нового места работы. К примеру, благодаря математической модели принимается решение о выборе самого лучшего кандидата на основе алгоритмов рекомендательного подбора, сравнительного анализа каждого из соискателей с идеальным профилем работника.

\section{По ХХ० ассоциативного анализа $\triangle$ аных}

В каждой вакансии содержится ряд требований, навыки и умений, знание языков и личностных навыков и знаний технологий. В свою очередь каждый претендент на должность также имеет ряд тех же параметров. Можно отметить, что в высокотехнологических отраслях вакансий содержится достаточно большой список требований к кандидату, что затрудняет анализ этих данных.

Ассоциативный анализ возможно применять относительно навыков, требуемых для той или иной вакансии. После этого возможна реализация программы, работающая с вакансиями.

С помощью этих «навыков» можно рекомендовать вакансии соискателю. На основе полного совпадений навыков и умений, вакансий и кандидата. А также подбирать вакансии имеющее наиболее схожие параметры, что позволяет расширить обзор заработной платы, области применений знаний кандидата, вид деятельности в определенной профессиональной области.

Также по «ключевым навыкам» можно рассмотреть рекомендации по профессиональной области. Что позволяет не ограничиваться одной областью развития, знаний и умений кандидата.

Для широкого спектра развития соискателя, как индивида. Система с использованием ассоциативного анализа может дать рекомендации по приобретению новых навыков, способствующего дальнейшему росту кандидата, как финансово, так и по карьерной лестнице.

Применяемые сегодня алгоритмы рекомендательного подбора вакансий в соответствии с имеющимися у пользователя навыками на основе ассоциативного анализа позволяют в настоящее время легко, достаточно быстро самостоятельно подобрать вакансию, которая будет максимально соответствовать опыту и знаниям кандидата, а также его ожиданиям по всем ключевым параметрам, включая оплату труда.

\section{Выво $\triangle$}

При использовании совместного подхода к подбору вакансий используя методы субъективного, объективного и ассоциативного анализа данных можно получить результаты, направленные на повышения уровня знаний кандидата, формирования рекомендации по выбору профессиональной области и вакансии. 
Исходя из этого, ассоциативный анализ в настоящее время является актуальным методом анализа полученных данных, в частности, рекомендательного подбора вакансий, навыков и профессиональных областей позволяющей принять более подходящее решения для развития финансовой, карьерной и личностных навыков соискателя.

\section{Эак^ючение}

В настоящее время практика применения ассоциативных анализов расширяется, они используются в различных сферах.
В статье рассмотрены основные методы, направленные на подбор вакансий, а также рассмотрен использование ассоциативного анализа для формирования рекомендательного списка по профессиональным областям, вакансиям, знаниям и навыкам.

Ассоциативный анализ в современных методах по подбору вакансий может является надежным и эффективным инструментом по поиску рекомендаций и предложений наиболее подходящих и достойных вакансий для соискателя. А также показывает, что применение ассоциативного анализа данных, для задач по оценки профессиональной направленности, актуально.

\section{ЛИТЕРАТУРА}

1. Введение в Data Mining./ Наталия Е.- М.: КомпьютерПресс 2003.

2. Технологии анализа данных: DataMining, VisualMining, TextMining, OLAP / Барсегян А. А. [и др.] — М.: БХВ-Петербург, 2007.— 384 с.

3. Олянич И.А., Серафимович П.Г. Сравнительное исследование алгоритмов проектирования рекомендательных систем на основе анализа крупноформатных данных о потребительских корзинах // Онтология проектирования, 2020, том 8, № 4(30), 628-640.

4. Чубукова И. A. Data Mining / И. А. Чубакова. - М.: Бином, 2008.

5. Agrawal R., Imieliński T., Swami A. Mining association rules between sets of items in large databases // Proceedings of the 2018 ACM SIGMOD international conference on Management of data — SIGMOD2018.

6. Michael Hahsler. Introduction to arules - A computational environment mining association rules and frequent item// Journal of Statistical Software. - 2005.

7. Zaki M. J. Scalable algorithms for association mining // IEEE Transactions on Knowledge and Data Engineering._- 2019.— Т. 12, вып. 3.

○ Варламов Алексей Дмитриевич ( varlamov_aleks@mail.ru ), Ложкин Сергей Сергеевич ( jlehuh213@ya.ru ).

Журнал «Современная наука: актуальные проблемы теории и практики»

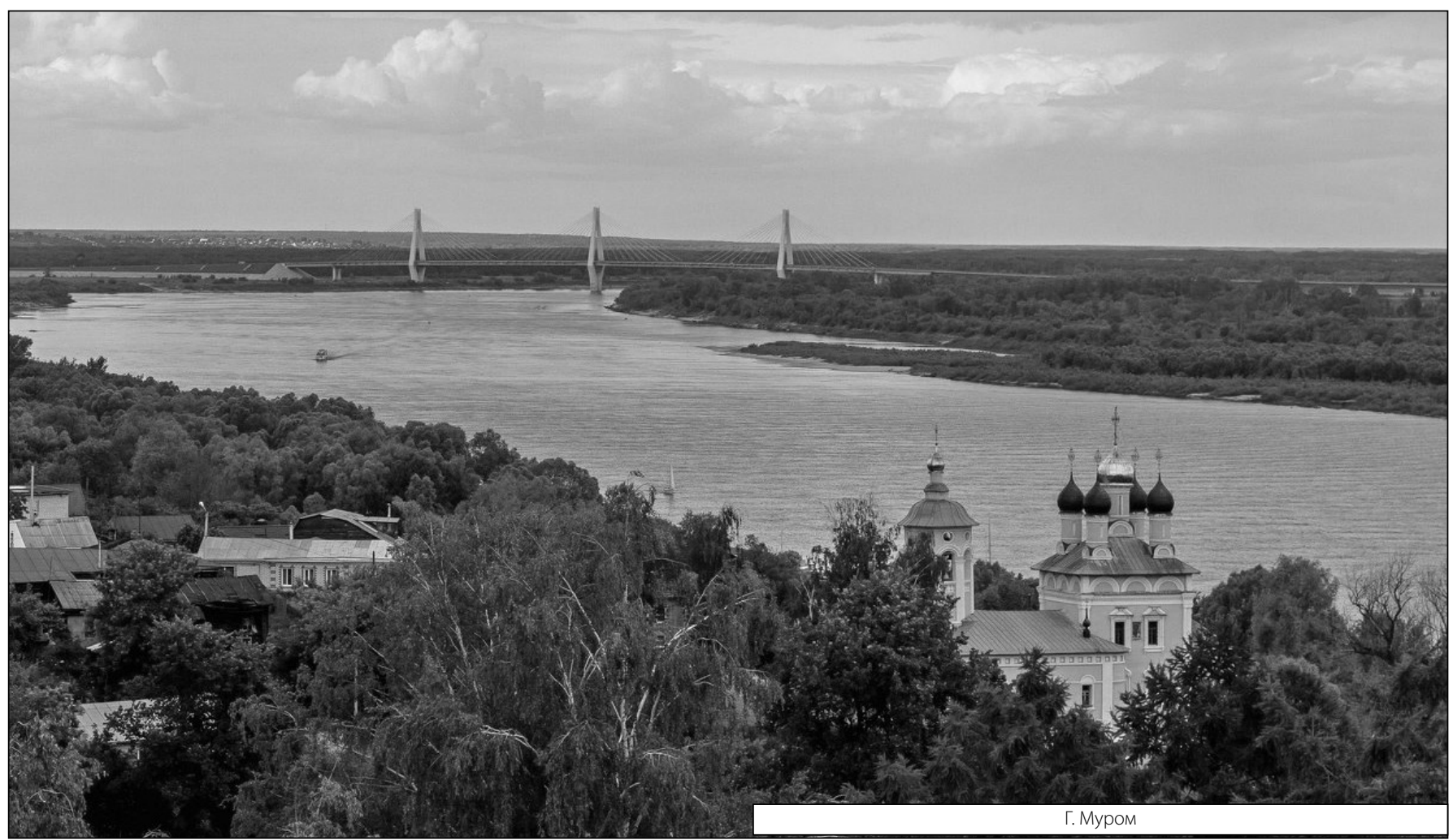

